DIW BERLIN

Discussion Papers

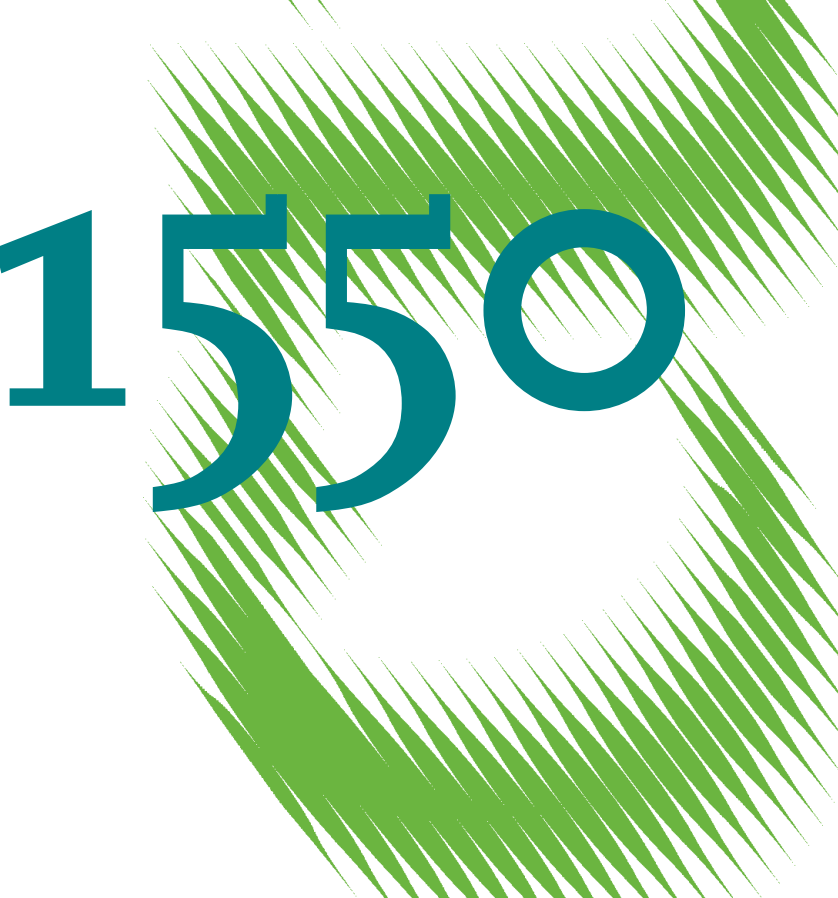

The State Dependent Impact of Bank Exposure on Sovereign Risk 
Opinions expressed in this paper are those of the author(s) and do not necessarily reflect views of the institute.

IMPRESSUM

(C) DIW Berlin, 2016

DIW Berlin

German Institute for Economic Research

Mohrenstr. 58

10117 Berlin

Tel. +49 (30) $89789-0$

Fax +49 (30) $89789-200$

http://www.diw.de

ISSN electronic edition 1619-4535

Papers can be downloaded free of charge from the DIW Berlin website:

http://www.diw.de/discussionpapers

Discussion Papers of DIW Berlin are indexed in RePEc and SSRN:

http://ideas.repec.org/s/diw/diwwpp.html

http://www.ssrn.com/link/DIW-Berlin-German-Inst-Econ-Res.html 


\title{
The State Dependent Impact of Bank Exposure on Sovereign Risk ${ }^{*}$
}

\author{
Maximilian Podstawski ${ }^{\dagger}$ and Anton Velinov ${ }^{\ddagger}$
}

This Version: February 11, 2016

\begin{abstract}
The theoretical literature remains inconclusive on whether changes in bank exposure towards the domestic sovereign have an adverse effect on the sovereign risk position via a diabolic loop in the sovereign-bank nexus or reduce perceived default risk by acting as a disciplinary device for the sovereign. In this paper we empirically analyze the impact of exogenous changes in bank exposure on the risk position of the sovereign within a Markov switching structural vector autoregressive in heteroscedasticity (MSH-SVAR) framework for a set of EMU countries. We add to the methodological literature by allowing for regime dependent shock transmissions according to the volatility state of the financial system. Finding support for both, a stabilizing and a destabilizing effect, we document a clear clustering among the country sample: Rising bank exposure increased default risk for the EMU periphery, but decreased credit risk for the core EMU countries during times of financial stress.
\end{abstract}

JEL classification: C32, E44, G10.

Keywords: Markov-switching, heteroscedasticity, identification, sovereign-bank interlinkages, sovereign risk, credit default swap, contagion.

${ }^{*}$ We are thankful to Benjamin Beckers, Christoph Große Steffen, Simon Junker, Helmut Lütkepohl, Malte Rieth, Tomasz Woz̀niak as well as the participants of the IAAE 2015 conference in Thessaloniki, the EEFS 2015 conference at the Centre for European Policy Studies Brussels, the WIEM 2015 conference in Warsaw, a Workshop at the University of Macedonia 2015, the DIW Berlin Macroeconometric Workshop 2014 and the Workshop Empirical Macroeconomics at Freie Universität Berlin 2015 for insightful discussions and helpful comments to earlier versions of this paper.

${ }^{\dagger}$ German Institute for Economic Research and Freie Universität Berlin; e-mail: mpodstawski@diw.de

${ }^{\ddagger}$ German Institute for Economic Research; e-mail: avelinov@diw.de 



\section{Introduction}

The most recent financial and (European) debt crises dealt a heavy blow to the financial stability of both governments and institutions alike. Throughout these crises two distinct phenomena were observed: First, sovereign and bank sector risk rose sharply and appear to move closely together. Second, the volume of domestic government debt held by the banking sector (which we will refer to as exposure in the following) has increased heavily (see Figure 1).
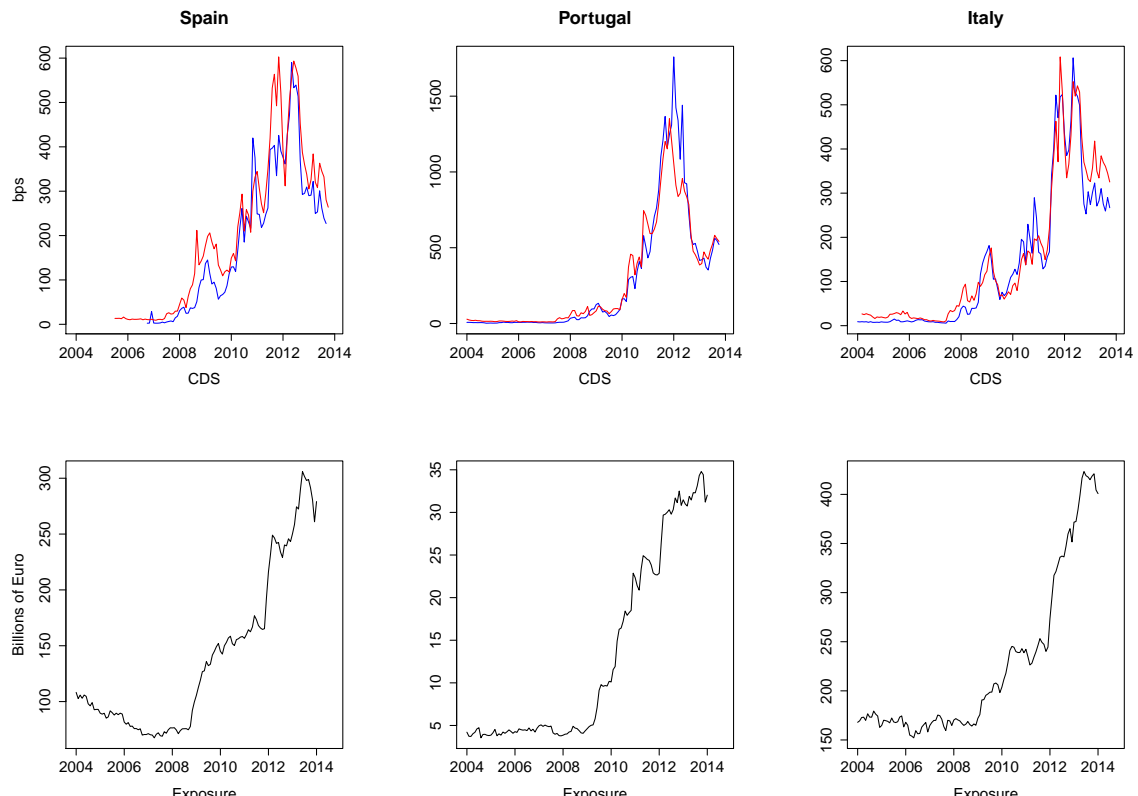

Figure 1: Government (blue) and banking sector (red) credit default swaps (CDS) in the Euro zone (Source: Datastream) and banking sector exposure toward domestic sovereign in the Euro zone (Source: ECB).

The role of bank exposure on financial stability is experiencing a lively debate in the literature. However, the literature appears to provide conflicting conclusions regarding the effect of increased domestic government debt holdings by banks on the government's credit risk. In their seminal paper on the sovereign-bank nexus, Brunnermeier et al. (2011) point out that high exposure potentially increases the risk positions of both the sovereign and its domestic banking system, via a so-called diabolic loop. They argue that speculation about the solvency of either of the two sectors would affect the risk position of the other, thus feeding back into a higher default risk for the first. Therefore, increases in exposure make twin crises (banking and sovereign) more likely and, thus, increase the probability of sovereign default. In contrast, the literature on sovereign default argues that bank exposure can act as a disciplinary device 
for the sovereign. Gennaioli et al. (2014) and Engler and Große Steffen (2016) show in the framework of theoretical models that a default is more costly to the sovereign if a relevant share of public debt is held by the domestic banking system. This triggers a credit crunch, thus reducing economic activity and worsening the sovereign's budget prospects. Due to costs of default increasing in the domestically held share of public debt, they claim that default risk on government debt falls with rising exposure. These two somewhat contradicting hypotheses from the sovereign-bank nexus and sovereign defaults literature are discussed in greater detail in Section 2.

In this paper we investigate the impact of exposure on sovereign risk from an empirical perspective for eight Euro area economies. In particular, we aim to determine which of the competing hypotheses has more support in the data. We investigate this issue within a Markov Switching Structural Vector Autoregressive in heteroscedasticity (MSH-SVAR) framework. Such models are well suited for the purpose of our analysis for several reasons. Firstly, from Figure 1 it is apparent that the data display structural breaks, occurring around crisis periods. Such periods can be thought of as being different states of nature, which are arguably well modelled with the Markov switching methodology (see for instance Hamilton, 1989). Our model is capable of endogenously determining different volatility states and, therefore, depicts crises as periods of increased volatility (see Velinov and Chen, 2015). Secondly, the heteroscedastic feature of our model allows us to test structural identifying restrictions as, for instance, in Lanne et al. (2010) and others (see Section 5). This is of particular interest as there are no restrictions that are well established in the literature that we can make use of to identify the structural model. Thirdly, the theoretical literature this empirical investigation is built upon implicitly differentiates between states of the economy and the financial system when deriving implied effects of bank exposure on sovereign risk. The sovereign-bank nexus literature, on the one hand, mainly refers to twin crises of banks and sovereigns during a phase of financial turmoil. The disciplinary mechanism underlying the argument in the sovereign default literature, on the other hand, is also likely to gain importance with rising financial distress as market participants may increase awareness and monitoring efforts regarding the sovereign's creditor decomposition. The model used in this paper, therefore, extends the classical Markov-switching in heteroscedasticity framework to allow for state dependent contemporaneous impact effects 
and shock transmission.

This paper contributes to the literature along two dimensions. Firstly, we empirically investigate the impact of bank exposure on sovereign credit risk (and hence, overall financial stability) in the Euro area. As far as we are aware, this issue is not yet investigated from an empirical perspective, even though the role of bank exposure is at the center of an intense policy debate. Pockrandt and Radde (2012) identify a range of regulatory incentives fostering the large observed increases in bank exposure and argue that they should be repealed in order to break the link between risk positions in both sectors. This development is particularly pronounced in times of ample liquidity in the banking sector (see Shambaugh, 2012), which was the case due to the European Central Banks's (ECB) unconventional monetary policy. Another explanation linking exposure to policy actions is provided by Merler and Pisani-Ferry (2012), who see persuasion by politicians as driving the purchase of sovereign debt by domestic banks. Given that the drivers of banking sector exposure identified in the literature are to a large extent at the discretion of policy makers, this renders the subject of investigation as highly policy relevant.

Secondly, we make a methodological contribution to the existing MSH-SVAR literature (see for instance Herwartz and Lütkepohl, 2014) by allowing for regime dependent shock transmission along the lines of Bacchiocchi and Fanelli (2015). The existing literature makes the implicit assumption that changes in observed volatility are solely attributable to the variance of structural shocks. This is a strong assumption and there is no clear reason to believe that the shock transmission should remain unaffected if an economy, for instance, enters a state of financial turmoil. In this paper the appeal of our model extension is that it allows us to identify regime dependent impacts of increases in exposure on the risk positions of the sovereign sector.

Based on the MSH-SVAR model, we find empirical support for the identifying restriction imposed on the system in order to identify the two shocks of interest, an exposure shock and a risk shock. Overall, our findings from the model with state invariant shock transmission point toward a destabilizing effect running from bank exposure to sovereign default risk in line with the literature on the sovereign-bank nexus. Impulse responses from models that allow for state dependent shock transmission, however, reveal a more differentiated picture. While the reaction of sovereign credit risk to changes in bank exposure is found to be particularly strong 
during turbulent times for the EMU periphery countries, it acts as a stabilizing device for a cluster of countries that were less affected by the crisis, supporting the theoretical predictions by the literature on sovereign defaults.

The remainder of the paper is structured as follows. The next section revisits the sovereignbank nexus and sovereign defaults literature, deriving the hypotheses that we empirically investigate. Section 3 introduces the data. In Section 4, we discuss the MSH-SVAR models and identification scheme used. Section 5 tests the identifying restriction using the data, presents smoothed state probabilities and assesses the hypotheses based on impulse responses. Finally, Section 6 concludes.

\section{Literature and hypotheses}

This section revisits two strands of literature that form the basis for competing hypotheses regarding the impact of bank sector exposure ${ }^{1}$ on sovereign default risk. We begin by discussing the so-called sovereign-bank nexus literature, leading to a diabolic loop hypothesis. We then turn to the sovereign defaults literature, leading to a disciplinary device hypothesis. Finally, we conclude the section with the derivation of a third hypothesis, emphasizing the regime dependency of the relationship between bank exposure and sovereign risk.

\section{Literature on the sovereign-bank nexus}

As evident from Figure 1, there is a clear tendency for the credit risk of banks and their respective sovereigns to move together. This phenomenon triggered a large strand of literature investigating the linkages between both sectors, establishing a diabolic loop of risk contagion (Brunnermeier et al. (2011)). We refer to this as the sovereign-bank nexus literature. A number of channels that connect both sectors together are identified. In what follows we discuss both directions separately, first the channels of contagion from the banking sector to the sovereign and then vice versa.

There are two main mechanisms identified as being responsible for potential contagion from the banking sector to the sovereign. Firstly, there is the credit supply channel. If the financial

\footnotetext{
${ }^{1}$ Note from Section 1 that we refer to exposure as the volume of national government debt held by the domestic banking sector.
} 
conditions of the banking sector were to deteriorate, banks may react by reducing credit supply to the real economy. This would lead to an economic slowdown or a deepening of an existing recession, which might severely harm the sovereign's tax base. The worsened fiscal position would reduce the sovereign's credit worthiness and, consequently, increase its default risk. Secondly, risks stemming from the banking sector might spill over to the national government via implicit bailout guarantees or, in a later stage, by explicit state promises (Ejsing and Lemke, 2011; Alter and Schüler, 2012; Kallestrup et al., 2013).

In the other direction, from the government to its banking sector, there is also risk contagion. It may take one of the following four channels. Firstly, given that banks generally hold nonnegligible amounts of public debt, an increase in the perceived likelihood of sovereign default would weaken the balance sheet positions of the banking sector. Angeloni and Wolff (2012), Buch et al. (2013) and De Bruyckere et al. (2013) provide evidence for the so-called portfolio channel during the European debt crisis. Secondly, a reduction of the market value of sovereign bonds has a direct negative impact on the funding conditions of banks, which use the bonds as collateral for refinancing operations (Kiyotaki and Moore (2005) and Kaminsky et al. (2003)); this is known as the collateral channel. Thirdly, Brown and Dinc (2011) and Demirgüç-Kunt and Huizinga (2010) point toward a guarantee channel: As soon as public debt default risk rises, government bank bailout and guarantee schemes become less worthy, which increases banking sector risk. Finally, Arezki et al. (2011) identify a sovereign rating channel. Since many rating agencies use public debt ratings as a ceiling for the private entities within an economy, a reduction in the sovereign rating may in turn lead to a reduction in the private rating.

The channels of contagion noted above are summarized in Figure 2. Given that risk spillovers work in both directions via a number of different channels, Acharya et al. (2014) and Rieth and Fratzscher (2014) among others, empirically identify a two way feedback between sovereign risk and bank risk. The paths of contagion outlined above result from domestic sovereign bond holdings by the banking sector, which hence lie at the core of the sovereign-bank nexus.

A measure to break the so called diabolic loop would have to target the amount of sovereign bonds held by banks: If the banks would hold less or no sovereign bonds, the link between financial and sovereign credit risk would become a lot weaker or vanish completely (Pockrandt 


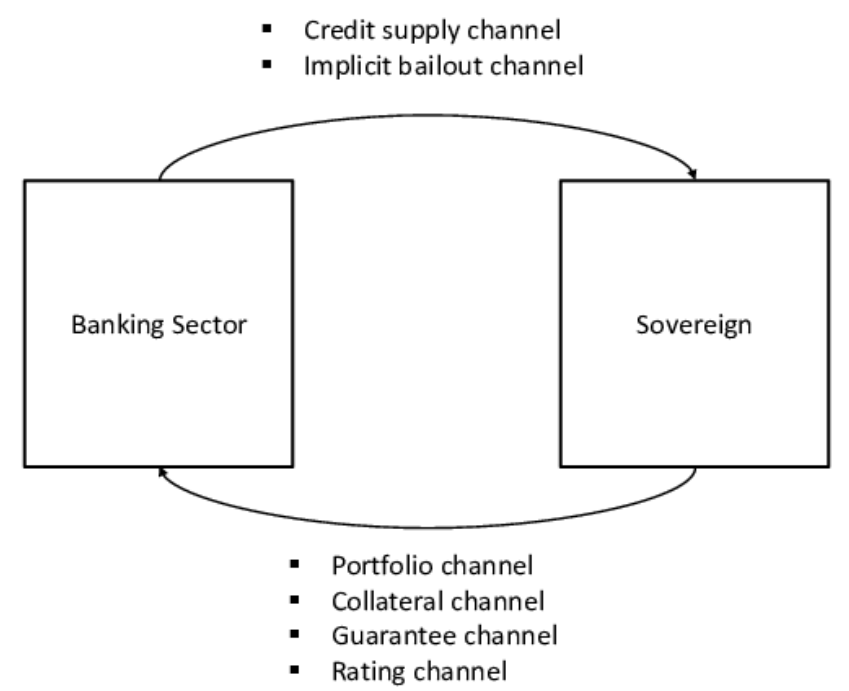

Figure 2: The main channels responsible for the diabolic loop transmission of contagion from both the banking sector and the domestic sovereign according to the bank nexus literature.

and Radde, 2012). Conversely, increases in exposure intensify the link between the two sectors, thus making twin crises more likely and, consequently, increasing the probability of sovereign default. Summing up, the literature on the sovereign-bank nexus implies that banking sector exposure to the domestic sovereign should generally have a destabilizing effect on the economy. Hence, we derive the following hypothesis based on this literature.

Hypothesis I (diabolic loop): Increases in bank sector exposure raise sovereign default risk via a diabolic loop of risk contagion.

\section{Literature on sovereign defaults}

Aside from the sovereign-bank nexus literature, another strand of literature related to this paper is on sovereign defaults. As opposed to private debt, where creditor rights in most countries are strong, it is not easy to enforce claims against governments in a similar manner. Therefore, sovereign debt can only exist because a default is costly to the government as the damage to the domestic economy (through the financial system) erodes the tax base. Borensztein and Panizza (2009) find that banking crises and credit crunches driven by debt defaults are particularly costly to the sovereign. The severity of such costs depends mainly on the extent of bank sector exposure.

Losses from default are more severe if debt is held by the domestic banking system. Gen- 
naioli et al. (2014) set up a model of sovereign default in which government defaults are costly because of the adverse effect on domestic banks' balance sheets. Consequently, their model predicts that sovereign default probability decreases in banking sector exposure. In addition, they find panel econometric evidence for sovereign defaults being less likely, the more exposed the domestic banking sector is. Similarly, Kohlscheen (2010) and Van Rijckeghem and Weder (2004) find governments are less likely to default on domestic creditors than foreign ones. Based on this line of reasoning, Engler and Große Steffen (2016) argue that incentives for sovereign default originate in wealth transfers by defaulting on foreign held debt. The fundamental point from this strand of literature is that bank exposure can act as a disciplinary device for the sovereign. Such a device would lead to a lower perceived sovereign default risk when more domestic debt is held by the banking system.

On a related point, the sovereign default literature helps explain the sharp increase in bank exposure observed in Figure 1. In particular, Broner et al. (2014) argue that sovereign bonds deliver a higher expected return to domestic creditors than to foreign creditors. Given that debt default is more costly to the sovereign if its debt is held domestically, government bonds offer a higher expected return to domestic creditors, especially during turbulent times. Therefore, public debt crises trigger a buy up of bonds by domestic creditors - most importantly banks.

Overall, the sovereign default literature points toward bank sector exposure acting as a disciplinary device. In other words, the greater the exposure of the domestic banking system, the less likely the government is to default on its debt. We formulate this in the following hypothesis.

Hypothesis II (disciplinary device): Increases in bank sector exposure raise the cost of default for the sovereign and, therefore, decrease sovereign default risk.

\section{State dependency}

From the above noted literature we further observe a certain degree of state dependence in the relation of bank exposure and sovereign risk. Given that the focus of the sovereign-bank nexus literature is on times of financial distress, we expect the diabolic loop mechanism to be particularly pronounced during those times. Financial market participants, for example, may become aware of a critically close linkage between banks and sovereigns, particularly during times of financial turmoil. 
Similarly, bank exposure may have a stronger disciplinary effect during times of fiscal stress. This could be due to rising awareness of the role of creditor composition for sovereign default decisions by market participants. By engaging in a closer monitoring of the debt composition, market participants are more likely to incorporate the degree of home bias in sovereign bond holdings in their credit risk assessment. During tranquil times with low default risk, however, such a mechanism might play only a minor role for the assessment of sovereign risk by financial markets.

It should be noted that there is no reason to assume that changes in exposure of domestic banks should even have a similar impact in terms of the sign across states. Increases in bank exposure may, for instance, have a stabilizing effect during tranquil times disciplining the sovereign, while acting as a destabilizing force during turbulent times in which the diabolic loop becomes dominant. We account for these considerations in our empirical setup.

In order to take into account the potential state dependence in the relationship of bank exposure and sovereign risk, we formulate the following third hypothesis.

Hypothesis III (state dependency): The effect of bank sector exposure on sovereign credit risk is state dependent and particularly pronounced during times of financial turmoil.

In what follows, we evaluate the hypotheses derived from the literature within a Markov Switching Structural Vector Autoregressive in heteroscedasticity (MSH-SVAR) framework. We test Hypothesis I and II by means of a state invariant shock transmission model (see Section 4.1.1). In order to test Hypothesis III we use a regime dependent shock transmission model (see Section 4.1.2). In the next section we briefly discuss how we construct our data set.

\section{Data}

Our analysis covers eight Euro area economies. Three of which - Italy, Portugal and Spain were hit hard by the European banking and sovereign debt crisis. The remaining five countries we investigate are Austria, Belgium, France, Germany and The Netherlands. These countries were less affected by the European banking and sovereign debt crisis, with Germany even being considered a so-called safe haven. We use monthly frequency data ranging from 2006:1 to 2014:1 for most countries. For Spain, The Netherlands and France the data start in 2006:10. 
Our data consist of sovereign credit default swaps $\left(C D S^{S o v}\right)$ and the log difference of bank sector exposure $(\Delta E x p)$. Data on CDS with five year maturity is obtained from Thomson Reuters Datastream. CDS are a commonly used proxy for sovereign credit risk as they insure the buyer against the potential loss from loan default. ${ }^{2}$ We measure changes in banks' exposure by the growth rate of the index of notional stocks of domestic public bonds held by the financial sector. ${ }^{3}$ An important feature of this series is that it is cleaned from effects of reclassification, revaluation, and exchange rate movements. Thus, changes in the level of this measure capture changes of the volume of bonds held on banks' balance sheets. Data on bank sector bond holdings is taken from the European Central Bank (ECB) Statistical Data Warehouse. All data is end of period data, i.e. from the last trading day in each month.

In addition, we collect a battery of exogenous control variables. These include total bonds issued by the government ${ }^{4}$ (to control for the scaling of total public debt), industrial production (as a control for potential business cycle effects), banking sector equity (as an indicator of banks' stability), stock market indices (to account for asset price developments), and a dummy variable for the announcement of the outright monetary transactions (OMT) in June 2012. ${ }^{5}$ The data for the control variables also stem from the ECB Statistical Data Warehouse and Thomson Reuters Datastream.

\footnotetext{
${ }^{2}$ Note that the price of CDS may be decomposed in the probability of default and the loss given default. Those components contribute to CDS prices approximately in a multiplicative manner. Throughout this paper we follow the convention in the literature of using time variation in CDS as a proxy for the variations in default probability, implicitly assuming the loss given default to remain constant over time.

${ }^{3}$ The index of notional stocks is superior to the simple balance sheet item as it is not clear whether balance sheet items are reported by book value or by market value. The ECB's manual on monetary financial institutions (MFI) balance sheet statistics remains imprecise on this issue (ECB, 2012, p. 74): "The ECB's preference is that in balance sheet reporting MFIs should present asset and liability positions at current market values or a close equivalent to market values (fair values), while accepting that in practice MFIs may continue to use local accounting rules requiring valuation other than current market values." This assumption might introduce some distortions in the estimation of structural shocks, given that those might not reflect movements in the volume of the bond holdings but rather underlying price movements. However, since we use the index of notional stocks for the balance sheet data, the adjustments should clean the data with respect to these considerations.

${ }^{4}$ We use a geometrically interpolated quarterly series to obtain a monthly frequency.

${ }^{5}$ In addition, we consider further control variables, such as the VIX volatility index, the spread of BBB and AAA rated corporate bonds, the announcement dates for the securitized market programme (SMP) and of the (very) long term refinancing operations ((V)LTRO) (to control for global risk appetite and the ECB's unconventional monetary policy). However, we find them to be insignificant in most cases and, hence, exclude them from the vector of exogenous variables. We also attempt to control for hedging efforts by banks toward sovereign default risk, but found such data not to be available.
} 


\section{The model}

This section describes the theoretical aspects of the models we use to test the hypotheses outlined in Section 2. It begins with a description of the general Markov Switching Vector Autoregressive (MS-VAR) model, then introduces two modeling approaches for the MS Structural VAR in heteroscedasticity (MSH-SVAR) model — with and without a regime dependent shock transmission. It describes how the structural shocks are identified and ends with a short note on bootstrapping.

\subsection{MS-VAR}

We consider the following reduced form $\operatorname{MS}-\operatorname{VAR}(p)$ model

$$
\begin{aligned}
y_{t}=\nu\left(S_{t}\right) & +A_{1}\left(S_{t}\right) y_{t-1}+A_{2}\left(S_{t}\right) y_{t-2}+\cdots+A_{p}\left(S_{t}\right) y_{t-p} \\
& +\Gamma_{0}\left(S_{t}\right) x_{t}+\Gamma_{1}\left(S_{t}\right) x_{t-1}+\cdots+\Gamma_{n}\left(S_{t}\right) x_{t-n}+D\left(S_{t}\right) z_{t}+u_{t},
\end{aligned}
$$

where $y_{t}$ is a $(K \times 1)$ vector of endogenous variables. In our case, $y_{t}=\left[C D S^{\text {Sov }}, E x p\right]^{\prime}$ (hence, $K=2)$. Further, $x_{t}$ is a vector of $N$ exogenous variables, $A_{i}$ 's $(K \times K)$ and $\Gamma_{j}$ 's $(K \times N)$ are parameter matrices with $i=1, \ldots, p$ and $j=1, \ldots, n$, where $n$ does not necessarily equal $p . z_{t}$ is a vector of $J$ dummy variables with a $(K \times J)$ coefficient matrix $D$ and $\nu$ is a $(K \times 1)$ vector of constant terms. Finally, $u_{t}$ is a $(K \times 1)$ vector of reduced form error terms with $E\left[u_{t}\right]=0$ and $E\left[u_{t} u_{t}^{\prime}\right]=\Sigma_{u}\left(S_{t}\right)$. In addition, we assume (for estimation purposes) that $u_{t}$ is normally and independently distributed conditional on a given state, hence,

$$
u_{t} \mid S_{t} \sim \operatorname{NID}\left(0, \Sigma_{u}\left(S_{t}\right)\right)^{6}
$$

All of the coefficient matrices are potentially governed by a first order discrete valued Markov process, $S_{t}$, that can take on $M$ different values, $S_{t}=1, \ldots, M$. In Section 5.1 we determine which parameters are allowed to switch by means of information criteria.

\footnotetext{
${ }^{6}$ This does not put any restriction on the unconditional distribution of $u_{t}$, which can take on a wide number of distributions see (see Hamilton, 1994, Chapter 22).
} 
The structural errors are related to the reduced form errors as

$$
u_{t}=B \varepsilon_{t},
$$

where $B$ is a $(K \times K)$ matrix of instantaneous effects (see Lütkepohl, 2005, Chapter 9) and $\varepsilon$ is a vector of structural errors. We now consider two modeling approaches for equation (3); a state invariant and state dependent $B$ matrix. In addition, we discuss how we identify the structural shocks in both model specifications - which we label as a sovereign risk shock, $\left(\varepsilon_{\text {risk }}\right)$ and an exposure shock, $\left(\varepsilon_{\text {exp }}\right)$.

\subsubsection{Invariant instantaneous impact matrix}

The state invariant approach is given in equation (3). In order to capture periods of different heteroscedasticity, we assume that $E\left[\varepsilon_{t}\right]=0$ and $E\left[\varepsilon_{t} \varepsilon_{t}^{\prime}\right]=\Lambda\left(S_{t}\right)$, a diagonal matrix, and that $\Lambda(1)=I_{K}$. Hence, $\operatorname{var}\left(u_{t} \mid S_{t}\right)=B \Lambda\left(S_{t}\right) B^{\prime}=\Sigma_{u}\left(S_{t}\right)$.

With this specification we use the following identification restriction

$$
\left(\begin{array}{l}
u_{1} \\
u_{2}
\end{array}\right)=\left(\begin{array}{cc}
b_{11} & 0 \\
b_{21} & b_{22}
\end{array}\right)\left(\begin{array}{l}
\varepsilon_{r i s k} \\
\varepsilon_{\text {exp }}
\end{array}\right) .
$$

This implies that a sovereign risk shock instantaneously effects both variables, sovereign CDS and bank exposure, while a bank exposure shock has no instantaneous impact on sovereign CDS. As noted in Section 3, we use end of period data for all endogenous variables and bank exposure data is published about two to four weeks after the respective month has ended. Hence, at the end of a respective period there is no contemporaneous information on bank exposure available to market participants. This means that a shock to bank exposure would not be known to the market instantaneously, which justifies a zero contemporaneous restriction. ${ }^{7}$

The restriction in equation (4) may be formally tested using over-identifying restrictions stemming from the heteroscedasticity in the data (see for instance Lanne et al., 2010; Herwartz and Lütkepohl, 2014; Velinov and Chen, 2015). In particular, it is necessary for the parameters

\footnotetext{
${ }^{7}$ Even without actual information on bank exposure, analysts might try and build expectations about shifts in bank balance sheets based on other information available to the market. However, we argue that such expectation building is accounted for by the autoregressive structure of the reduced form VAR model.
} 
of at least one of the $\Lambda\left(S_{t}\right), S_{t}=2, \ldots, M$ matrices to be distinct. If that is the case then the $B$ matrix is identified up to changes in sign and column ordering. Any additional restrictions on $B$ then become over-identifying and can be tested. Note that for a model with two states, we are left with five unknowns (three elements of $B$ and two of $\Lambda(2)$ ), which are related to the six unique variance parameters from $\Sigma_{u}(1)$ and $\Sigma_{u}(2)$. Hence, the model would be over-identified and the zero restriction could be tested. ${ }^{8}$

\subsubsection{State dependent instantaneous impact matrix}

The second modeling approach considers a state dependent $B$ matrix, which, following Bacchiocchi and Fanelli (2015), is given as

$$
B\left(S_{t}\right)=B^{I N V}+Q\left(S_{t}\right)
$$

Here $B^{I N V}$ is a $(K \times K)$ matrix of state invariant instantaneous effects and $Q\left(S_{t}\right)$ is a $(K \times K)$ matrix of varying instantaneous effects for a given state, with $Q(1)=0$, a matrix of zeros. Note that with this approach we have $\operatorname{var}\left(u_{t} \mid S_{t}\right)=B\left(S_{t}\right) B\left(S_{t}\right)^{\prime}=\Sigma_{u}\left(S_{t}\right)$ (see equation (2)), hence, $E\left[\varepsilon_{t} \varepsilon_{t}^{\prime}\right]=I_{K}$ (naturally, $\left.E\left[\varepsilon_{t}\right]=0\right)$.

This state dependent instantaneous impact model allows impulse responses (IRs) to vary over regimes according to the contemporaneous impacts of a shock. Therefore, the model has sufficient degrees of freedom to investigate the third hypothesis, which posits state dependent signs of the impulse responses.

To identify the structural shocks $\left(\varepsilon_{\text {risk }}\right.$ and $\left.\varepsilon_{\text {exp }}\right)$ in the state dependent instantaneous effects model, we use the same restriction on $B^{I N V}$ as given in Equation (4). In addition, we allow some of the elements of $Q\left(S_{t}\right), S_{t}>1$ to vary. Formally, we use the following matrix specification of Equation (5)

$$
B^{I N V}=\left(\begin{array}{cc}
b_{11} & 0 \\
b_{21} & b_{22}
\end{array}\right), \quad Q(1)=\left(\begin{array}{ll}
0 & 0 \\
0 & 0
\end{array}\right) \quad \text { and } \quad Q\left(S_{t}\right)=\left(\begin{array}{cc}
q_{11}\left(S_{t}\right) & q_{12}\left(S_{t}\right) \\
0 & 0
\end{array}\right) \forall S_{t}>1
$$

This means that the upper right element, $b_{12}\left(S_{t}\right)$ of $B\left(S_{t}\right)$, is unrestricted for $S_{t}>1$, or, in

\footnotetext{
${ }^{8}$ The pair of elements of $\Lambda(2)$ need to be distinct so that $\Sigma_{u}(1) \neq \Sigma_{u}(2)$ (recall, $\Lambda(1)=I_{2}$ ).
} 
other words, for high volatility states (see Section 5.2).

We use the specification in equation (6) for several reasons. Firstly, over the course of the most recent crises market participants have become more sensitive toward potential risk contagion between banks and sovereigns. This has arguably induced closer monitoring than before. We, therefore, feel more comfortable only imposing the restriction for the lower volatility state. Secondly, we need to provide the model with enough flexibility so as to investigate the third hypothesis. Put differently, if we keep the zero restriction in all states, the responses we are interested in (namely those of sovereign CDS toward exposure shocks) remain invariant up to scaling.

Finally, we assure that the necessary and sufficient conditions for (local) identification of the model are satisfied, given the set of restrictions that we impose. ${ }^{9}$

\subsection{Estimation and Bootstrapping}

We now discuss parameter estimation for both types of model specifications, with and without a state invariant $B$ matrix, and we briefly describe how we test the identifying restriction in equation (4). This section concludes with a note on bootstrapping.

The model parameters in equation (1) are estimated by means of the expectation maximization (EM) algorithm (see Hamilton, 1994, Chapter 22). To estimate the parameters of the state invariant $B$ matrix in equation (3) and of $\Lambda\left(S_{t}\right), S_{t}>1$, we use a similar algorithm as that described in (Velinov and Chen, 2015, Appendix). The model with state dependent $B$ matrix in (5) is estimated based on the following concentrated out log likelihood function in

${ }^{9}$ The rank condition is satisfied if the $K(K+1) \times a$ matrix given by

$$
\left(I_{2} \otimes D_{K}^{*}\right)\left(\begin{array}{cc}
\left(B \otimes I_{K}\right) & 0_{K^{2} \times K^{2}} \\
(B+Q) \otimes I_{K} & (B+Q) \otimes I_{K}
\end{array}\right)\left(\begin{array}{cc}
S_{B} & S_{I} \\
0_{K^{2} \times a_{C}} & S_{Q}
\end{array}\right)
$$

has full column rank (see Bacchiocchi and Fanelli, 2015, equation (27)), where $a$ is the number of free parameters in the structural impact matrices $B$ and $Q, S_{B}, S_{Q}$ and $S_{I}$ summarize the linear restrictions on $B, Q$ and crossrestrictions on $B$ and $Q$, respectively, and $D_{K}^{*}$ is the Moore-Penrose inverse of the duplication matrix $D$. We draw 100,000 matrices from the uniform distribution on the interval between -10 and 10 and find the rank condition satisfied for every draw. 
the maximization step of the EM algorithm

$$
\begin{aligned}
l\left(B^{I N V}, Q(2), Q(3) \ldots, Q(M)\right) & =\frac{1}{2} \sum_{m=1}^{M}\left[\widehat { T } _ { m } \operatorname { l o g } \left(\operatorname{det}\left(B(m) B(m)^{\prime}\right)\right.\right. \\
& \left.+\operatorname{tr}\left(\left(B(m) B(m)^{\prime}\right)^{-1} \sum_{t=1}^{T} \widehat{\xi}_{m t \mid T} \widehat{u}_{t} \widehat{u}_{t}^{\prime}\right)\right]
\end{aligned}
$$

where $\xi_{m t \mid T}, m=1, \ldots, M, t=1, \ldots, T$ are the model smoothed probabilities and $T_{m}=$ $\sum_{t=1}^{T} \xi_{m t \mid T}$. The remaining parameters are defined as in equation (1). The hat denotes estimated parameters.

Once the EM algorithm has converged, standard errors of the point estimates of the parameters are obtained through the inverse of the negative of the Hessian matrix evaluated at the optimum. With the standard errors in hand, we use Wald tests to determine whether the pairwise parameters of at least one of the $\Lambda\left(S_{t}\right), S_{t}=2, \ldots, M$ matrices are distinct. As noted in Section 4.1.1, if that is the case then the $B$ matrix is identified up to changes in sign and column ordering. Hence, any additional restrictions as in equation (4) become over-identifying and can be tested by means of a Likelihood Ratio (LR) test.

Finally, we would like to mention the theoretical aspects of the bootstrapping procedure we use for generating confidence bands for our impulse responses (see Section 5.3). In particular, given the heteroscedastic nature the data, ${ }^{10}$ classical residual based bootstrap techniques may be problematic in generating reliable confidence intervals for impulse responses (IRs). Any re-sampling scheme would need to preserve the second order characteristics of the data. We therefore, use the following bootstrap method to generate artificial series for IR confidence intervals

$$
\begin{aligned}
y_{t}^{*}=\widehat{\nu}\left(\widehat{S}_{t}\right) & +\widehat{A}_{1}\left(\widehat{S}_{t}\right) y_{t-1}^{*}+\widehat{A}_{2}\left(\widehat{S}_{t}\right) y_{t-2}^{*}+\cdots+\widehat{A}_{p}\left(\widehat{S}_{t}\right) y_{t-p}^{*} \\
& +\widehat{\Gamma}_{0}\left(\widehat{S}_{t}\right) x_{t}+\widehat{\Gamma}_{1}\left(\widehat{S}_{t}\right) x_{t-1}+\cdots+\widehat{\Gamma}_{n}\left(\widehat{S}_{t}\right) x_{t-n}+\widehat{D}\left(\widehat{S}_{t}\right) z_{t}+u_{t}^{*},
\end{aligned}
$$

where $\widehat{S}_{t}$ is derived from the rounded smoothed state probabilities (so that it takes on an integer value) and $u_{t}^{\star}=\varphi_{t} \widehat{u}_{t}$, where $\varphi_{t}$ is a random variable, independent of $y_{t}$ following a Rademacher

\footnotetext{
${ }^{10} \mathrm{ARCH}$ tests strongly indicate the existence of heteroscedasticity in the data.
} 
distribution. $^{11}$ In other words, $\varphi_{t}$ is either 1 or -1 with a $50 \%$ probability.

\section{Results}

This section presents the empirical results of both models (see Section 4.1.1 and 4.1.2) for eight Euro area countries. Impulse responses (IRs) are presented to assess the three hypotheses. The section starts with a discussion of the model specification and smoothed probabilities.

\subsection{Model selection}

In our analysis we consider two-state Markov Switching Structural Vector Autoregressive in heteroscedasticity (MSH-SVAR) models. The use of two states is for several reasons. Firstly, due to a limited number of observations, we prefer parsimonious model specifications. Secondly, two states are sufficient to formally test the identifying restriction imposed on the model (see Section 4.1). Thirdly, provided one state is interpretable as a tranquil and the other as a crisis state, two states suffice for testing the third hypothesis that refers to a state dependent shock transmission. Finally, a third state would mainly pick up outliers, rendering the parameters for this state difficult to estimate due to few observations.

We follow the literature on MS-VAR models and select the lag order of the endogenous variables, $p$ (see equation (1)), based on the linear VAR model. To keep the models as parsimonious as possible we follow the Bayesian information criterion (BIC) and choose one lag for Spain, Italy, Portugal, Belgium and Germany and two lags for France, The Netherlands and Austria. In addition, we set $n=p$, that is we use the same lag length for the exogenous variables.

Table 1 reports information criteria for different specifications regarding the linearity of the model. Clearly, non-linear models are preferred over linear specifications, according to log-likelihoods and information criteria. For Spain, Germany, The Netherlands and Austria, the AIC favors models with more parameters switching. For the remainder of the countries both criteria indicate models without switching slope parameters. Based on our preference

\footnotetext{
${ }^{11}$ Davidson and Flachaire (2008) show that using the Rademacher distribution for Wild bootstrapping is superior to the two-point distribution proposed by Mammen (1993), even if the residuals are not symmetrically distributed. See MacKinnon (2014) for a further discussion of Wild bootstrap auxiliary distributions.
} 
Table 1: Log-Likelihood, Akaike and Bayesian information criteria for model selection based on a Markov-switching model with two states and different sets of switching parameters $\left(\right.$ Note: $\Sigma\left(S_{t}\right)-$ only covariance matrix switching; $\Sigma\left(S_{t}\right), \nu\left(S_{t}\right)$ - covariance matrix and intercept switching; $\Sigma\left(S_{t}\right), A_{i}\left(S_{t}\right)$ covariance matrix and slope parameters switching; $\Sigma\left(S_{t}\right), A_{i}\left(S_{t}\right), \nu\left(S_{t}\right)$ - all reduced form parameters switching)

\begin{tabular}{llccccc} 
& & linear & $\Sigma\left(S_{t}\right)$ & $\Sigma\left(S_{t}\right), \nu\left(S_{t}\right)$ & $\Sigma\left(S_{t}\right), A_{i}\left(S_{t}\right)$ & $\Sigma\left(S_{t}\right), A_{i}\left(S_{t}\right), \nu\left(S_{t}\right)$ \\
\hline \multirow{3}{*}{ Spain } & LogLik & -711.32 & -686.68 & -675.47 & -673.73 & -662.5 \\
& AIC & 1476.64 & 1435.36 & $\mathbf{1 4 1 8 . 9 3}$ & 1419.47 & 1436.99 \\
& BIC & 1542.9 & 1511.81 & $\mathbf{1 5 0 2 . 7 8}$ & 1508.24 & 1575.09 \\
\hline \multirow{3}{*}{ Italy } & LogLik & -746.53 & -694.57 & -693.87 & -717.26 & -692.83 \\
& AIC & 1547.06 & $\mathbf{1 4 5 1 . 1 4}$ & 1455.73 & 1506.53 & 1497.67 \\
& BIC & 1616.3 & $\mathbf{1 5 3 0 . 6 4}$ & 1542.92 & 1598.85 & 1641.27 \\
\hline \multirow{3}{*}{ Portugal } & LogLik & -949.09 & -862.5 & -860.98 & -860.36 & -862.16 \\
& AIC & 1952.17 & $\mathbf{1 7 8 6 . 9 9}$ & 1787.95 & 1790.73 & 1834.32 \\
& BIC & 2021.41 & $\mathbf{1 8 6 6 . 4 9}$ & 1872.57 & 1880.48 & 1975.36 \\
\hline \multirow{3}{*}{ Belgium } & LogLik & -693.04 & -636.75 & -635.91 & -634.87 & -641.23 \\
& AIC & 1440.08 & $\mathbf{1 3 3 5 . 5 1}$ & 1337.81 & 1339.73 & 1392.46 \\
& BIC & 1509.31 & $\mathbf{1 4 1 5}$ & 1422.44 & 1429.48 & 1533.5 \\
\hline \multirow{6}{*}{ Germany } & LogLik & -686.54 & -599.23 & -597.03 & -596.13 & -558.91 \\
& AIC & 1427.08 & 1260.46 & 1260.06 & 1262.26 & $\mathbf{1 2 2 7 . 8 2}$ \\
& BIC & 1496.32 & $\mathbf{1 3 3 9 . 9 5}$ & 1344.69 & 1352.02 & 1368.86 \\
\hline \multirow{2}{*}{ France } & LogLik & -616.46 & -564.19 & -560.77 & -560.59 & -549.93 \\
& AIC & 1294.92 & 1198.39 & $\mathbf{1 1 9 7 . 5 3}$ & 1209.19 & 1227.86 \\
& BIC & 1371 & $\mathbf{1 2 8 7 . 7 7}$ & 1294.58 & 1321.56 & 1391.31 \\
\hline \multirow{2}{*}{ Netherlands } & LogLik & -638.26 & -590.87 & -591.34 & -597.65 & -574.17 \\
& AIC & 1338.51 & $\mathbf{1 2 5 1 . 7 4}$ & 1258.67 & 1283.3 & 1276.34 \\
& BIC & 1414.6 & $\mathbf{1 3 3 7 . 2 4}$ & 1351.49 & 1390.78 & 1432.67 \\
\hline \hline \multirow{2}{*}{ Austria } & LogLik & -721.48 & -641.64 & -640.66 & -630.2 & -624.78 \\
& AIC & 1504.96 & 1353.27 & 1357.32 & $\mathbf{1 3 4 8 . 4}$ & 1377.56 \\
& BIC & 1584.45 & $\mathbf{1 4 4 2 . 6 6}$ & 1454.36 & 1460.77 & 1541.01 \\
\hline \multirow{2}{*}{} & & & & & &
\end{tabular}

for parsimonious model specifications, we opt for the more conservative BIC. In most cases it strongly favors a model structure with only switching covariance matrices. Therefore, we use a Markov Switching Structural Vector Autoregressive in heteroscedasticity (MSH-SVAR) model for all countries considered. Such a specification is in line with the findings from ARCH tests for heteroscedasticity in the data. These tests strongly reject the null hypothesis of no heteroscedasticity. 


\subsection{Smoothed state probabilities}

Figure 3 plots the smoothed probabilities of state 2, the high volatility state, for all eight countries based on the MS model with the state invariant instantaneous impact matrix. ${ }^{12}$ Clearly, each MS model is well capable of capturing the crisis phases, which are always indicated as being in state $2 .^{13}$

The upper four Panels of Figure 3 show the countries that were affected somewhat more by the crisis (Spain, Portugal, Italy and Belgium). Their smoothed probabilities appear to be relatively stable. The lower four Panels of the figure show the more stable countries (France, Germany, The Netherlands and Austria), where Germany was even regarded as a safe haven during the European debt crisis. The smoothed probabilities of Germany, The Netherlands and Austria show more volatile patterns. This is likely attributable to less volatility in data, making both states not very different from each other.

In order to test the identifying restriction in equation (4), we first need to determine whether the pairwise diagonal elements of $\Lambda(2)$ are distinct (see Section 4.1.1 and 4.2). Table 2 clearly shows that this is the case according to Likelihood Ratio (LR) tests (the null hypothesis is $\left.\lambda_{11}(2)=\lambda_{22}(2)\right) .{ }^{14}$ This means that all of the estimated models are over-identified since $\Sigma(1) \neq \Sigma(2)$. Table 3 summarizes the LR tests of the validity of the over-identifying restriction on the matrix of structural impact parameters $B$. The null hypothesis is $B$, as in equation $(4)$, i.e. $b_{12}=0$, versus the alternative of an unrestricted $B$ matrix. The restriction is strongly supported by the data, except in the case of the Spanish model. We consider this result as a strong signal in support of our identifying assumption and proceed with testing the hypotheses formulated in Section 2. Since most elements of $\Lambda(2)$ are larger than unity (i.e. the volatility of the first state), we refer to the second state as the crisis state. ${ }^{15}$

\footnotetext{
${ }^{12}$ Note that the smoothed state probabilities for the model with a state dependent instantaneous impact matrix look quite similar, but are not identical.

${ }^{13}$ Note that the states are not directly comparable among different countries. For instance, volatility may be higher in the second state for some countries than for others indicating that they were hit more strongly by the crisis.

${ }^{14}$ Although we follow the literature on identification via heteroscedasticity regarding the assumptions on the asymptotic distribution of the test statistic, it should be noted that research shows these assumptions are not quite correct. Therefore, these tests should be interpreted with some caution. However, the (bootstrapped) IRs stemming from the models identified via heteroscedasticity do not indicate any lack of identification since error bands are well behaved.

${ }^{15}$ Note that we are mainly interested in $\lambda_{1}$, the CDS volatility in the second state, which is always greater than one (see Table 2).
} 


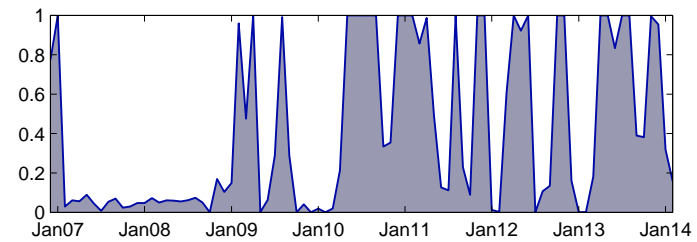

(a) Spain

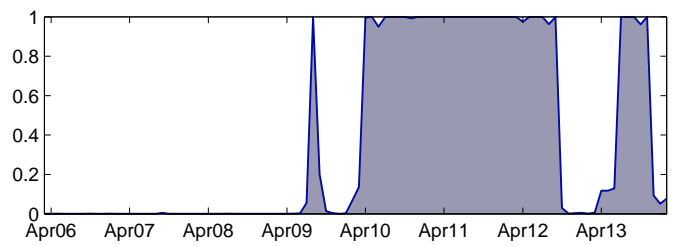

(c) Italy

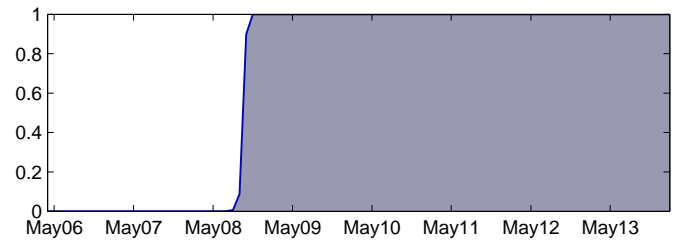

(e) France

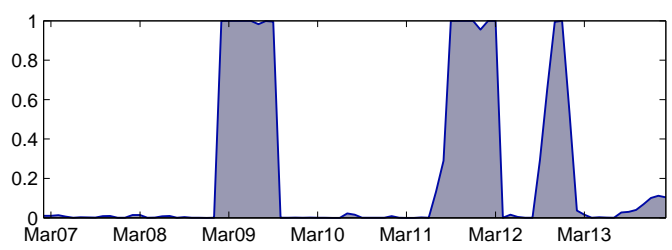

(g) Netherlands

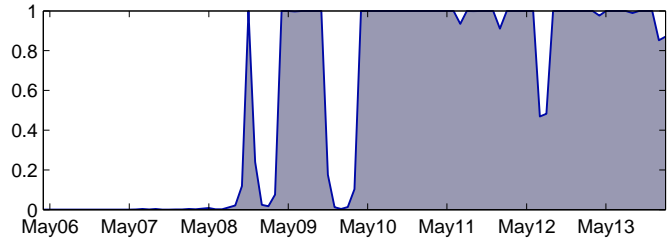

(b) Portugal

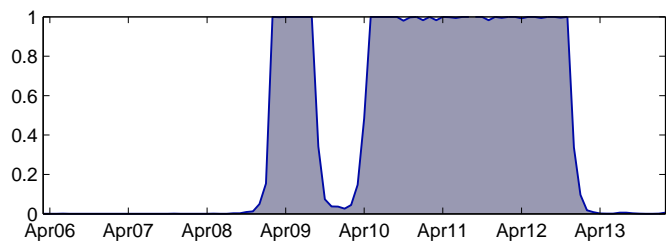

(d) Belgium

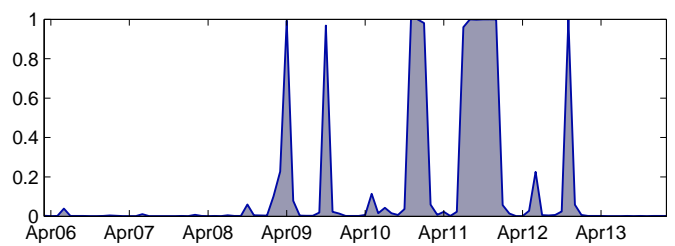

(f) Germany

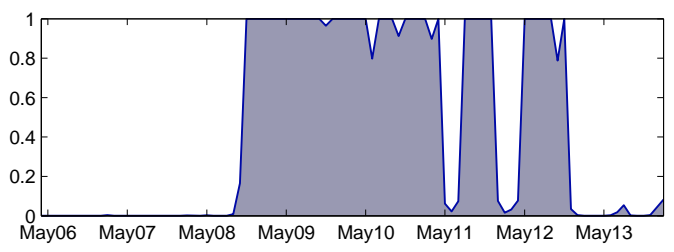

(h) Austria

Figure 3: Smoothed probabilities from the Markov switching VAR models with invariant structural impact matrices 
Table 2: Diagonal elements of $\Lambda(2)$ with standard errors in parentheses. Likelihood Ratio test for distinct elements of $\Lambda(2)$. The null hypothesis is $\lambda_{11}(2)=\lambda_{22}(2)$.

\begin{tabular}{lcccccccc} 
& Spain & Italy & Portugal & Belgium & Germany & France & Netherlands & Austria \\
\hline$\lambda_{1}$ & 54.13 & 185.05 & 188.12 & 62.68 & 14.33 & 130.87 & 36.73 & 136.86 \\
& $(17.77)$ & $(6.01)$ & $(23.00)$ & $(50.35)$ & $(5.91)$ & $(6.05)$ & $(5.67)$ & $(139.80)$ \\
$\lambda_{2}$ & 0.19 & 1.89 & 5.89 & 0.99 & 79.84 & 1.95 & 0.05 & 10.23 \\
& $(0.09)$ & $(0.83)$ & $(2.47)$ & $(0.31)$ & $(13.41)$ & $(0.53)$ & $(0.02)$ & $(4.09)$ \\
\hline LogLik & -590.71 & -696.08 & -690.97 & -655.06 & -609.08 & -890.41 & -664.2 & -602.65 \\
$\chi^{2}$ & 28.62 & 12.8 & 55.84 & 55.79 & 6.91 & 53.72 & 36.89 & 26.85 \\
p-value & 0 & 0 & 0 & 0 & 0.01 & 0 & 0 & 0 \\
\hline
\end{tabular}

Table 3: Likelihood ratio test of the restriction in equation (4) versus an unrestricted $B$ matrix.

\begin{tabular}{lcccccccc} 
& Spain & Italy & Portugal & Belgium & Germany & France & Netherlands & Austria \\
\hline Restr. & -687.78 & -694.57 & -862.5 & -636.75 & -599.23 & -564.19 & -590.87 & -641.64 \\
Unrestr. & -681.77 & -694.53 & -862.49 & -636.31 & -599.2 & -563.85 & -590.63 & -641.63 \\
\hline$\chi^{2}$ & 12.01 & 0.09 & 0.01 & 0.89 & 0.06 & 0.69 & 0.48 & 0.01 \\
p-value & 0 & 0.76 & 0.91 & 0.34 & 0.8 & 0.41 & 0.49 & 0.93 \\
\hline
\end{tabular}

\subsection{Impulse Responses}

We turn to impulse response (IR) analysis to formally test the hypotheses outlined above.

We evaluate Hypotheses I and II using the state invariant $B$ model, since they do not refer to a regime dependent shock transmission. We assess Hypothesis III by means of the regime dependent $B$ model.

\subsubsection{State invariant $B$ impulse responses}

Figure 4 reports the IRs in state 1 of sovereign CDS to a positive one standard deviation exposure shock. Note, the IRs of state 2 are the same in shape, sign and significance, only differing in the scaling on the vertical axis. All countries exhibit a significant increase in credit risk as a response to a shock in bank exposure.

The overall responses are not only statistically significant, they are also economically significant. The countries in the upper panel of the figure that were hit harder by the sovereign debt crisis exhibit particularly strong responses. For instance, the model indicates an increase in CDS of up to 10 basis points for Italy and more than 20 basis points for Spain and Portugal. In addition, for those countries, the responses do not show signs of mean reversion at the 20 

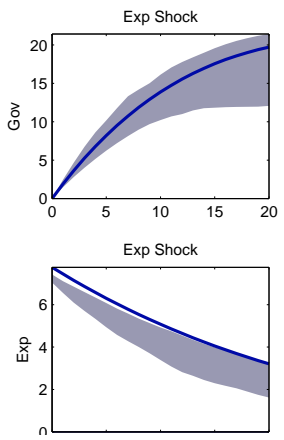

(a) Spain
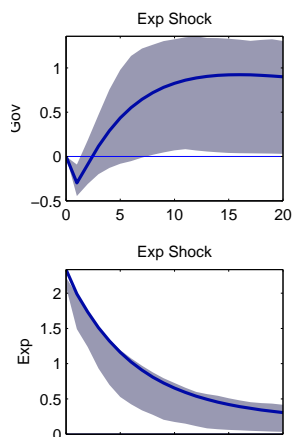

(e) France

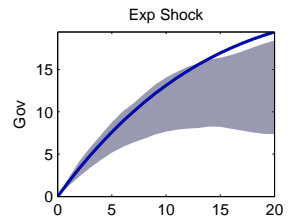

Exp Shock

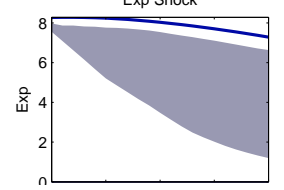

(b) Portugal

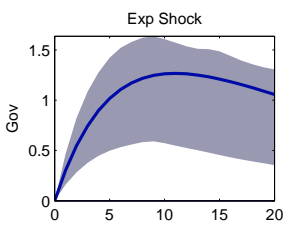

Exp Shock

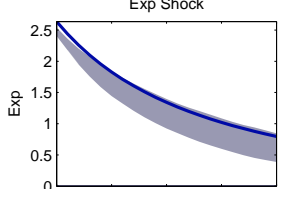

(f) Germany

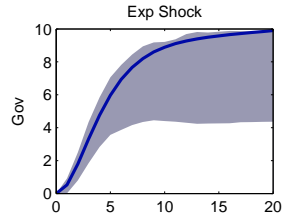

Exp Shock

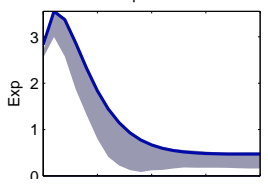

(c) Italy

Exp Shock

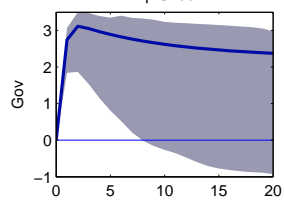

Exp Shock

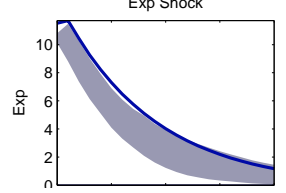

(g) Netherlands

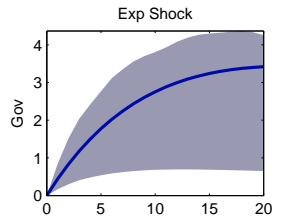

Exp Shock

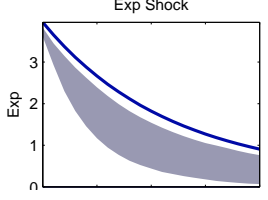

(d) Belgium
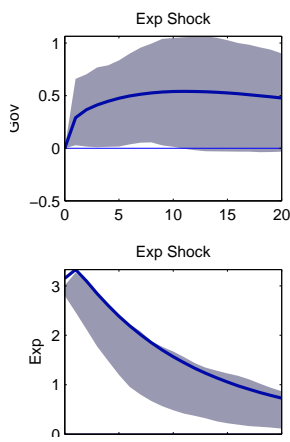

(h) Austria

Figure 4: State invariant $B$ impulse responses of sovereign CDS to an exposure shock with $68 \%$ confidence intervals based on 1000 bootstrap replications

month horizon plotted in the figure. Whereas for Germany, The Netherlands and Austria the IRs also show longer lasting impacts, but with a clear reversion toward mean after a couple of months.

Overall, we conclude that the results from models with state invariant structural impact matrices seem to point strongly toward the diabolic loop story (Hypothesis I), thereby, rejecting competing Hypothesis II, the disciplinary device mechanism hypothesis.

\subsubsection{State dependent $B$ impulse responses}

We now turn to the state dependent $B$ model results in order to test Hypothesis III. These allow for contemporaneous reactions of the sovereign CDS markets to changes in banks' balance sheets (i.e. increases in bank exposure toward the sovereign, during crises times). Figures 5 and 6 plot these IRs for the low and high volatility states, respectively. Note, that for tranquil times, the contemporaneous restriction still holds, identifying the exposure shock as argued in 

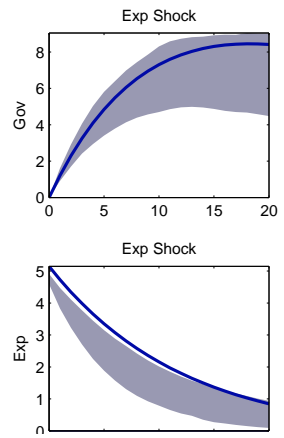

(a) Spain
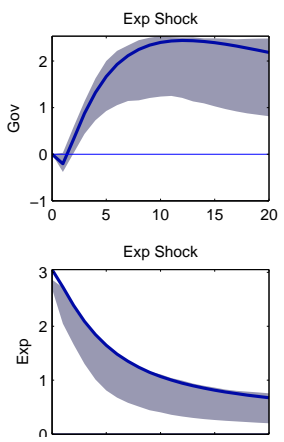

(e) France

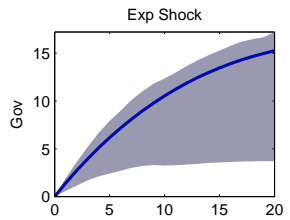

Exp Shock

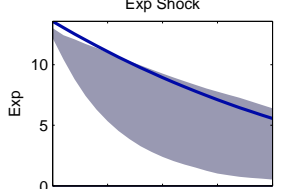

(b) Portugal

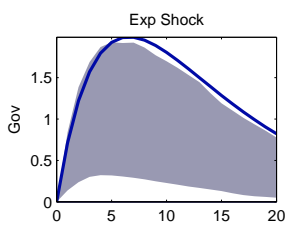

Exp Shock

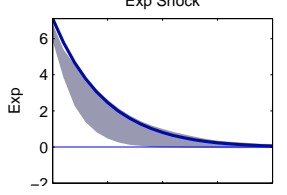

(f) Germany

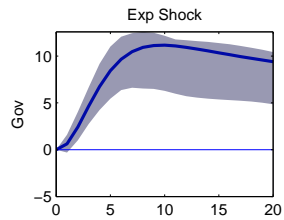

Exp Shock

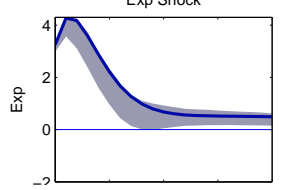

(c) Italy

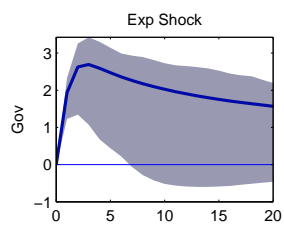

Exp Shock

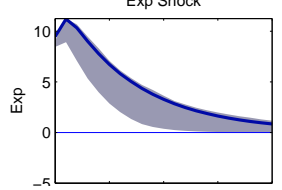

(g) Netherlands

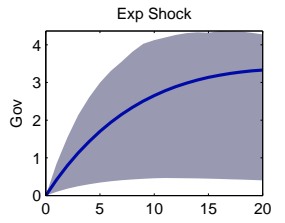

Exp Shock

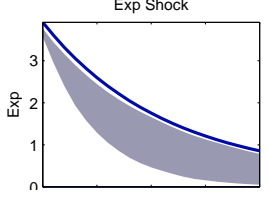

(d) Belgium
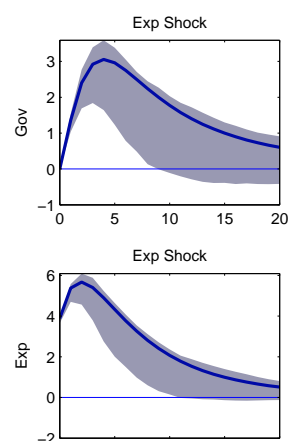

(h) Austria

Figure 5: State dependent $B$ impulse responses of sovereign CDS to an exposure shock for the low volatility state with $68 \%$ confidence intervals based on 1000 bootstrap replications

\section{Section 4.1.2.}

A number of findings arise from Figure 6. Firstly, the IRs of state 1, the tranquil state, are qualitatively very similar to the ones from the state invariant $B$ model. This is as expected, given that the identification has not changed for the tranquil state. Secondly, for state 2, the crisis state, the impact responses plotted in Figure 6 are all different from zero - due to the higher degree of freedom in estimating the impact matrix. Finally, the impulse responses portray a clear clustering of the countries, dividing them by the sign of the impact response into a group that was hit hard by the crisis and a group with sovereign finances less affected by the crisis.

Sovereign credit risk rises strongly in Spain, Portugal and Italy in response to an exposure shock. The impulse responses exhibit a clear pattern of regime dependence and point toward a strong diabolic loop effect at play in the crisis hit countries. On impact, an increase in exposure of one standard deviation leads to a jump of between 20 and 40 basis points in credit default swaps. There is no evidence of bank exposure acting as a disciplinary device for these countries 

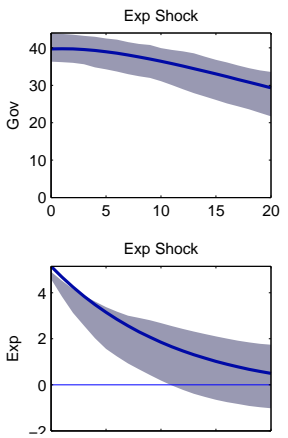

(a) Spain
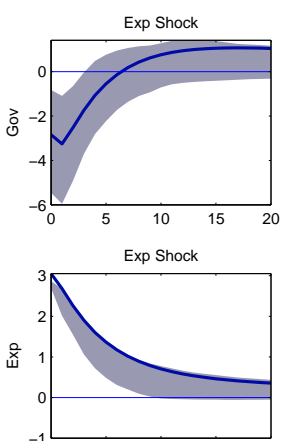

(e) France
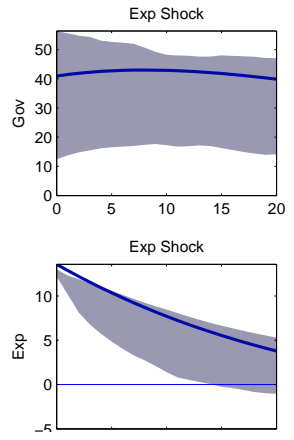

(b) Portugal

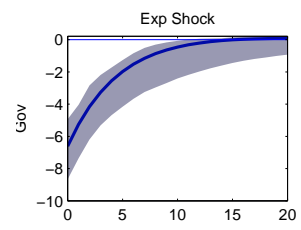

Exp Shock

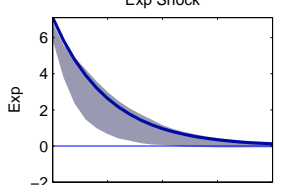

(f) Germany

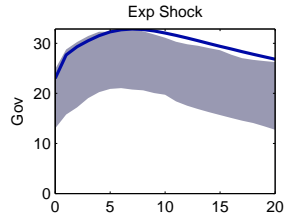

Exp Shock

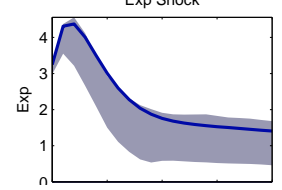

(c) Italy

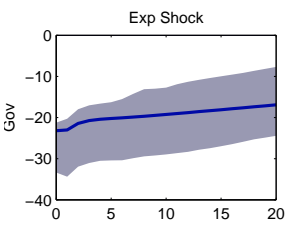

Exp Shock

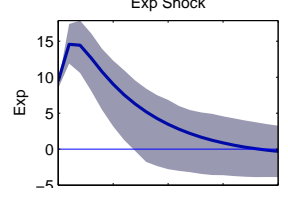

(g) Netherlands

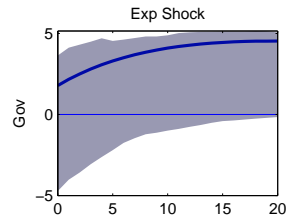

Exp Shock

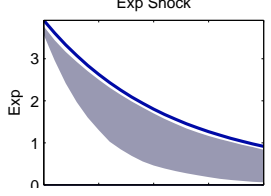

(d) Belgium
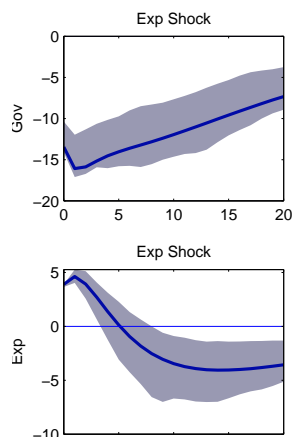

(h) Austria

Figure 6: State dependent $B$ impulse responses of sovereign CDS to an exposure shock for the high volatility state with $68 \%$ confidence intervals based on 1000 bootstrap replications

in either regime.

The effect runs in the opposite direction for the countries less affected by financial distress during the sovereign debt crisis: Increased bond holdings in the domestic banking sector reduce sovereign credit risk in France, Germany, The Netherlands and Austria. This evidence indicates that domestic bond holdings may have a disciplining effect on some governments. Given the clear clustering of the countries, this may be related to the room for maneuver that is left for governments to take home bias in bond holdings into account in their decision process.

Overall, the state dependent $B$ model partly supports the findings from the state invariant model and points toward a diabolic loop at play for the sample of crisis countries, Spain, Italy and Portugal. For these economies there seems to be positive feedback between risk in the banking sector and sovereign risk running via sovereign bonds held by domestic banks. While this effect is rather small and, thus, economically less relevant in tranquil times, it seems to be particularly pronounced during crisis times - in line with the predictions of the sovereign-bank nexus literature. 
However, we also identify a stabilizing effect during times of financial distress running from bank exposure to sovereign risk for the group of core countries, France, Germany, The Netherlands and Austria, thus supporting the disciplinary device hypothesis. This may be due to a rising awareness of the degree of bank exposure to sovereign risk and, hence, its consequences for public default during turbulent times. Indeed, there is a body of literature documenting how increased awareness of fundamentals determined sovereign risk during the European public debt crisis (Bekaert et al., 2011; Beirne and Fratzscher, 2013; D'Agostino and Ehrmann, 2014).

In summary, the results based on the state dependent $B$ model point toward a strong regime dependence (Hypothesis III) and the existence of both a stabilizing and a destabilizing effect (Hypotheses I and II) running from bank exposure to sovereign risk. A drawback of our modeling approach is that there is no leeway to draw conclusions on the economic factors that determine which of the two effects — diabolic loop or disciplinary device — dominate. While this may be related to factors like the awareness by markets of economically significant sovereign default risk in the first place and subsequent room for maneuver on the side of the sovereign to react to changes in the structure of its creditors, we leave it to future research to investigate these determinants.

\section{Conclusion}

During the European debt crisis, banks heavily increased their domestic bond holdings. The theoretical literature remains inconclusive as to whether increasing exposure has an adverse effect on the risk positions of the domestic sovereign via a diabolic loop or whether it reduces perceived credit risk by acting as a disciplinary device for the sovereign.

In this paper we analyze the impact of exogenous changes in bank exposure on the risk positions of the sovereign within a Markov Switching Structural Vector Autoregressive in heteroscedasticity (MSH-SVAR) framework. We add to the methodological literature by allowing for regime dependent shock transmissions according to the state of the financial system.

The MSH-SVAR model captures higher volatility phases during the crisis periods in a plausible manner. Based on Likelihood Ratio tests, the imposed short-run restriction that is used for identification of a bank exposure shock is widely accepted. 
There is strong evidence for the existence of a destabilizing effect running from bank exposure to sovereign default risk in the countries hardest hit by the crisis, namely Spain, Italy and Portugal. This effect is particularly pronounced during phases of financial turmoil and supports the hypothesis of bank exposure being a key ingredient of a diabolic loop mechanism. On the other hand, we find a stabilizing effect from increased bank exposure during turbulent times for the countries less hit by the crisis, namely France, Germany, The Netherlands and Austria. This points toward exposure potentially acting as a disciplinary device in line with the sovereign defaults literature.

While the findings underpin the importance of efforts to break the sovereign-bank nexus by reducing the home bias in sovereign bond holdings, regulators should also take into account the potentially stabilizing force of exposure of the banking sector toward sovereign risk. Future research should investigate the determinants of the effect running from bank exposure to sovereign risk, leading to an adverse effect for some sovereigns and a stabilizing one for others. 


\section{References}

Acharya, V., I. Drechsler, and P. Schnabl (2014). A pyrrhic victory? bank bailouts and sovereign credit risk. The Journal of Finance 69(6), 2689-2739.

Alter, A. and Y. S. Schüler (2012). Credit spread interdependencies of european states and banks during the financial crisis. Journal of Banking \& Finance 36(12), 3444-3468.

Angeloni, C. and G. B. Wolff (2012). Are banks affected by their holdings of government debt? Bruegel Working Paper (717).

Arezki, R., B. Candelon, and A. Sy (2011). Sovereign rating news and financial markets spillovers: Evidence from the european debt crisis. IMF working papers, 1-27.

Bacchiocchi, E. and L. Fanelli (2015). Identification in structural vector autoregressive models with structural changes, with an application to us monetary policy. Oxford Bulletin of Economics and Statistics $77(6), 761-779$.

Beirne, J. and M. Fratzscher (2013). The pricing of sovereign risk and contagion during the european sovereign debt crisis. Journal of International Money and Finance 34, 60-82.

Bekaert, G., M. Ehrmann, M. Fratzscher, and A. J. Mehl (2011). Global crises and equity market contagion. NBER Working Papers (17121).

Borensztein, E. and U. Panizza (2009). The costs of sovereign default. IMF Staff Papers 56(4), $683-741$.

Broner, F., A. Erce, A. Martin, and J. Ventura (2014). Sovereign debt markets in turbulent times: Creditor discrimination and crowding-out effects. Journal of Monetary Economics 61, $114-142$.

Brown, C. O. and I. S. Dinc (2011). Too many to fail? Evidence of regulatory forbearance when the banking sector is weak. Review of Financial Studies 24(4), 1378-1405.

Brunnermeier, M., L. Garicano, P. Lane, M. Pagano, R. Reis, T. Santos, S. Van Nieuwerburgh, and D. Vayanos (2011). European safe bonds: ESBies. Euro-nomics.com. 
Buch, C. M., M. Koetter, and J. Ohls (2013). Banks and sovereign risk: A granular view. Deutsche Bundesbank Discussion Paper (29/2013).

D'Agostino, A. and M. Ehrmann (2014). The pricing of g7 sovereign bond spreads: The times, they are a-changin. Journal of Banking \& Finance 47, 155-176.

Davidson, R. and E. Flachaire (2008). The wild bootstrap, tamed at last. Journal of Econometrics 146(1), 162-169.

De Bruyckere, V., M. Gerhardt, G. Schepens, and R. Vander Vennet (2013). Bank/sovereign risk spillovers in the european debt crisis. Journal of Banking 8 Finance 37(12), 4793-4809.

Demirgüç-Kunt, A. and H. Huizinga (2010). Bank activity and funding strategies: The impact on risk and returns. Journal of Financial Economics 98(3), 626-650.

ECB (2012). Manual on MFI balance sheet statistics, April 2012.

Ejsing, J. and W. Lemke (2011). The janus-headed salvation: Sovereign and bank credit risk premia during 2008-2009. Economics Letters 110(1), 28-31.

Engler, P. and C. Große Steffen (2016). Sovereign risk, interbank freezes, and aggregate fluctuations. European Economic Review (forthcoming).

Gennaioli, N., A. Martin, and S. Rossi (2014). Sovereign default, domestic banks, and financial institutions. The Journal of Finance 69(2), 819-866.

Hamilton, J. D. (1989). A new approach to the economic analysis of nonstationary time series and the business cycle. Econometrica 57, 357-384.

Hamilton, J. D. (1994). Time Series Analysis, Volume 2. Princeton University press.

Herwartz, H. and H. Lütkepohl (2014). Structural vector autoregressions with Markov switching: Combining conventional with statistical identification of shocks. Journal of Econometrics $183(1), 104-116$.

Kallestrup, R., D. Lando, and A. Murgoci (2013). Financial sector linkages and the dynamics of bank and sovereign credit spreads. Working Paper. 
Kaminsky, G. L., C. Reinhart, and C. A. Vegh (2003). The unholy trinity of financial contagion. Journal of Economic Perspectives 17, 51 - 74.

Kiyotaki, N. and J. Moore (2005). Liquidity and asset prices. International Economic Review $46(2), 317-349$.

Kohlscheen, E. (2010). Domestic vs external sovereign debt servicing: An empirical analysis. International Journal of Finance 86 Economics 15(1), 93-103.

Lanne, M., H. Lütkepohl, and K. Maciejowska (2010). Structural vector autoregressions with markov switching. Journal of Economic Dynamics and Control 34(2), 121-131.

Lütkepohl, H. (2005). New introduction to multiple time series analysis. Springer Verlag (Berlin).

MacKinnon, J. G. (2014). Wild cluster bootstrap confidence intervals. Queen's University Working Papers 1329.

Mammen, E. (1993). Bootstrap and wild bootstrap for high dimensional linear models. The Annals of Statistics 21, 255-285.

Merler, S. and J. Pisani-Ferry (2012). Who's afraid of sovereign bonds? Bruegel Policy Contribution 2012/02.

Pockrandt, J. and S. Radde (2012). Need for reform of EU banking: Decoupling the solvency of banks and sovereigns. DIW Economic Bulletin 2(11), 11-18.

Rieth, M. and M. Fratzscher (2014). Monetary policy, bank bailouts and the sovereign-bank risk nexus in the euro area. CEPR Discussion Paper (10370).

Shambaugh, J. C. (2012). The euro's three crises. Brookings Papers on Economic Activity 44(1), $157-231$.

Van Rijckeghem, C. and B. Weder (2004). The politics of debt crises. CEPR Discussion Papers (4683).

Velinov, A. and W. Chen (2015). Do stock prices reflect their fundamentals? new evidence in the aftermath of the financial crisis. Journal of Economics and Business 80, 1-20. 